\title{
HIV induced suppression of host immunity: relevance to Mycobacterium tuberculosis infections
}

\author{
Ambak Kumar Rai ${ }^{1}$, Dipendra Kumar Mitra ${ }^{2}$ \\ ${ }^{1}$ Department of Biotechnology, Motilal Nehru National Institute of Technology Allahabad, Allahabad-211004, India \\ ${ }^{2}$ Cellular Immunology Laboratory, Department of Transplant Immunology and Immunogenetics, All India Institute of Medical \\ Sciences (A.I.I.M.S.), New Delhi-110029, India
}

\begin{abstract}
Compromised immunity among human immunodeficiency virus (HIV) infection attracts some of the most notorious opportunistic infections (OIs) like Mycobacterium tuberculosis etc. The increased burden of HIV tuberculosis (HIV-TB) cases also increases their transmission rate in the community. Chemotherapy presumably brings down the viral number below certain threshold number, which can be successfully contained by the host immune response. An impaired immunity, not only facilitates the dissemination of virus, but also fails to mount sufficient level of effector immune response to inhibit the OIs. In general, the outcome of the infection is decided by the equilibrium between the host's effector immune response and extent of immune suppression, which facilitates immune evasion strategies evolved by the virus. During HIV infection, perturbation of immune homeostasis results from alteration in the representation of various fine $\mathrm{T}$ cell subsets, performing highly selective immune functions. This appears to have critical impact on effector T cell responses that keep the viral load under check and maintain latency of M. tuberculosis infection including other OIs. However, the precise role of these suppressor cells on the immune response among HIV infected individuals remains far from conclusive. Any alteration in frequency and function of these fine $\mathrm{T}$ cells that regulates the terminal effector response against latent $M$. tuberculosis infection, plausibly results in perturbation of immunity ending in reactivation of $M$. tuberculosis infection. The present review focuses the immunopathogenesis, immune suppression, and reactivation of $M$. tuberculosis among HIV infected patients.
\end{abstract}

HIV AIDS Rev 2017; 16, 3: 140-154

DOI: https://doi.org/10.5114/hivar.2017.66899

Key words: HIV, opportunistic infection, M. tuberculosis, immune response, immune suppression.

\section{Introduction}

Human immunodeficiency virus (HIV) infection causes the fatal disease acquired immune deficiency syndrome (AIDS), which brings significant numbers of death worldwide annually. Approximately, 1.1 million people died from AIDS related illness in 2015 [1]. The gravity of the prob- lem is further aggravating with the increase in new cases per year (2.1 million new cases of HIV infection in 2016) $[1,2]$. Conditions are worrying in Eastern Europe and Central Asia, where the rate of new HIV infections has increased by $57 \%$ in 2015 . Although the patients can be managed with the chemotherapy, while with the emergence of opportunistic infections (OIs), particularly tuberculosis (TB),
Address for correspondence: Dr. Ambak Kumar Rai, Assist. Prof., Department of Biotechnology, Motilal Nehru National Institute of Technology Allahabad, Allahabad-211004, India,

phone: 91-532-2271241, fax: 91-5322545341,

e-mail: ambakrai@mnnit.ac.in

\section{Article history:}

Received: 15.07.2016

Received in revised form: 21.11.2016

Accepted: 6.12.2016

Available online: 30.03 .2017
International Journal of HIV-Related Problems

HIV \& AIDS

R e vi e w 
the condition of the patients gets worse and they respond poorly to their management [3-6]. Compromised immunity among HIV infection attracts some of the most notorious opportunistic infections like Mycobacterium tuberculosis, Leishmania donovani, Pneumocystis, Cryptococcus and many viral infections etc. $[7,8]$. As per the Joint United Nations Programme on HIV/AIDS (UNAIDS), TB-related deaths among people living with HIV have decreased by $32 \%$. But, TB remains the leading cause of death among people living with HIV (33\%) [9]. With the growing awareness, the initiation of highly active anti-retroviral therapy (HAART) and an increase in the coverage of HAART, the new infections as well as AIDS related death have significantly fallen. It has been more significant among children, where the new HIV infections have declined by $50 \%$, since 2010 worldwide [9]. The slow decline in the new HIV infection has raised alarming concern in last five years. Highly active anti-retroviral therapy, a milestone in the treatment of HIV-AIDS, presumably brings down the viral load below certain threshold number, which can be successfully contained by the host immune response. However, an impaired immunity not only facilitates the dissemination of virus, but also fails to mount sufficient level of effector immune response to inhibit the diseases like tuberculosis and other OIs as well [10, 11]. Furthermore, it is believed that the level of immunity imposed by the host decides the spectrum of HIV infection (asymptomatic vs. symptomatic) and progression of tuberculosis. In general, the outcome of the infection is decided by the equilibrium between the host's effector immune response and the level of immune suppression, which facilitates immune evasion strategies evolved by the virus.

HIV epidemic has caused a prominent alteration in the epidemiology and clinical manifestation of several opportunistic infections, with TB being the commonest one $[12,13]$. Besides the social factors like stigma, ignorance, and misunderstanding in socio-economically oppressed population, this is mainly due to the fact that containment of these pathogens critically requires certain levels of host immune response, which is compromised by the HIV infection. This has propelled the epidemic of TB, particularly in developing subcontinents like India and Africa $[14,15]$. This is due to the rampant previous exposure of individuals to M. tuberculosis (prior to acquisition of HIV infection) resulting in latent TB infection (LTBI), only if the individuals have sufficient level of immunity and can contain the disease [13]. HIV infection compromises the immune system and increases the reactivation of LTBI and individual susceptibility to TB infection $[13,16]$. HIV infection not only increases the risk of reactivation of LTBI, but also enhances the risk of rapid progression to clinical TB soon after fresh infection and disseminated forms of TB such as extrapulmonary TB including miliary TB. Alarmingly, suppressed state of host T cell function among HIV infected individuals, increases the susceptibility to development of multi drug resistant (MDR) TB [16]. In HIV-negative persons infected with M. tuberculosis, the lifetime risk of developing clinical TB ranges between 10-20\%. Whereas, in persons co-infected with $M$. tuberculosis and
HIV, the annual risk of fresh M. tuberculosis infection exceeds by $10 \%$. Mycobacterium tuberculosis infection accounts for $26 \%$ of AIDS-related death in a year [17]. The increased burden of HIV-TB cases also increases M. tuberculosis transmission rates in the community [12]. Elicitation of a strong host CD4+ T cell response is an essential prerequisite for containment of viral, primarily due to their intracellular habitat in macrophages, an inaccessible site for antibody mediated effector mechanisms $[18,19]$. HIV primarily infects and destroys CD4+ T cells [18]. Elicitation of a strong host T cell response is an essential prerequisite for containment of $M$. $t u$ berculosis infection and other chronic intracellular OIs. During HIV infection, perturbation of immune homeostasis results from alteration in the representation of various fine $\mathrm{T}$ cell subsets including regulatory $\mathrm{T}$ (Treg) cells performing distinct immune functions [20]. This appears to have critical impact on effector $\mathrm{T}$ cell responses that keep the viral load under check and maintain latency of $M$. tuberculosis infection including other OIs. However, the precise identification of phenotypically distinct $\mathrm{T}$ cell subsets and their intricate interaction leading to perturbed effector immune function responsible for containing $M$. tuberculosis infection, thus keeping the bacillary infection in latency (or dormancy) remains enigmatic.

This review deals with the immunosuppression among HIV patients and the factors responsible for reactivation of latent infection of M. tuberculosis. It would also be very interesting to discuss the component of immunosuppression with progression of TB infection among HIV infected patients (asymptomatic to full blown AIDS). Despite decrease in CD4+ T cells, patients mount certain immune response, though it remains insufficient to M. tuberculosis. Here, we attempt to take a deeper and detailed insight on the issue and its relevance.

\section{Chronology of immunopathogenesis in HIV-TB}

The silent entry of HIV in our body through some limited route (sexual, transfusion, and mother-child etc.) is marked by its capacity to utilize some of the immune co-receptors (CD4, CCR5, and CXCR4). CD4, a high affinity receptor for gp120, is expressed by a subset (Th) of T cells, and by macrophages $(\mathrm{m} \varphi)$ and dendritic cells (DCs) [18]. CD4 alone is insufficient for the entry of virus. When gp120 binds with CD4, it undergoes conformational changes leading to creation of another site, which interacts with either CCR5 or CXCR4. Depending on their affinity to CCR5 and CXCR4, viruses are categorized in R5 and X4 strains, respectively [21]. Since CCR5 is expressed by T cells as well as monocytes, R5 strain (M-tropic) can infect both types of cells. Whereas X4 strain (T-tropic) can infect only CD4+ $\mathrm{T}$ cells, because CXCR4 is expressed majorly by T cells. So, using term 'M-tropic' to refer R5 strain is misleading and inappropriate. It is observed that the R5 strain initiates, establishes and transmits the infection. Once the infection is established, it is taken over by more deadly X4 strain [21]. 
This sophisticated entry inside the immune cells allows them to escape the initial combat and manipulate the immune response. After entering inside the cells with the help of gp41, viral genetic material either survives in episomal form or enters within the nucleus and gets integrated in the host genome (latency) [22].

The infection of HIV starts from asymptomatic to symptomatic, and then full blown AIDS. These stages can be monitored by clinical evaluation, measuring CD4 count and/or viral load. Immunologically, these stages significantly differ, particularly in terms of CD4+ T cell response $[23,24]$. In untreated patients with progressive disease, the early HIV infection is characterized by high viral loads and decreasing CD4+ T cell counts, which lead to AIDS associated illness and OIs. It is also seen that the relentless but eventually rapid loss in CD4+ T cells are not only because of selective depletion by $\operatorname{HIV}[25,26]$, but also the decreased development of CD4+ T cells from precursor cells in thymus [27]. The early peak (acute phase) in the viral load is followed by the surge in antigen specific
CD8+ T cells. Instituting HAART among these patients, results in decline of the viral load followed by antigen specific CD8+ T cells (chronic phase) $[28,29]$. Furthermore, these antigen specific CD8+ T cells lower down in number, proliferate, and maintain their number unless there is rise in viral load (Figure 1). During this process, HIV infected monocyte $(\mathrm{mo}) / \mathrm{m} \varphi$ travel all along the body and reaches to the various organs including privileged sites and resides there [30]. Various clinical complications are triggered by the inflammatory signals initiated either by the recruited $\mathrm{mo} / \mathrm{m} \varphi$ and/or by newly infected resident cells [31-34]. For examples, the infected $\mathrm{mo} / \mathrm{m} \varphi$ traffics through the blood brain barrier and enters the brain, infects resident cells and initiate the inflammatory cascade [35]. Otherwise, the resident cells (microglial cells), a second route, may secrete chemotactic attractants under the influence of some secretary mediators and allow the recruitment of infected mo/ $\mathrm{m} \varphi$ cells $[30,35,36]$.

Though the CD4+T cells are critical for the intactness of the immune system, virus first infects $\mathrm{mo} / \mathrm{m} \varphi / \mathrm{DC}$ in-

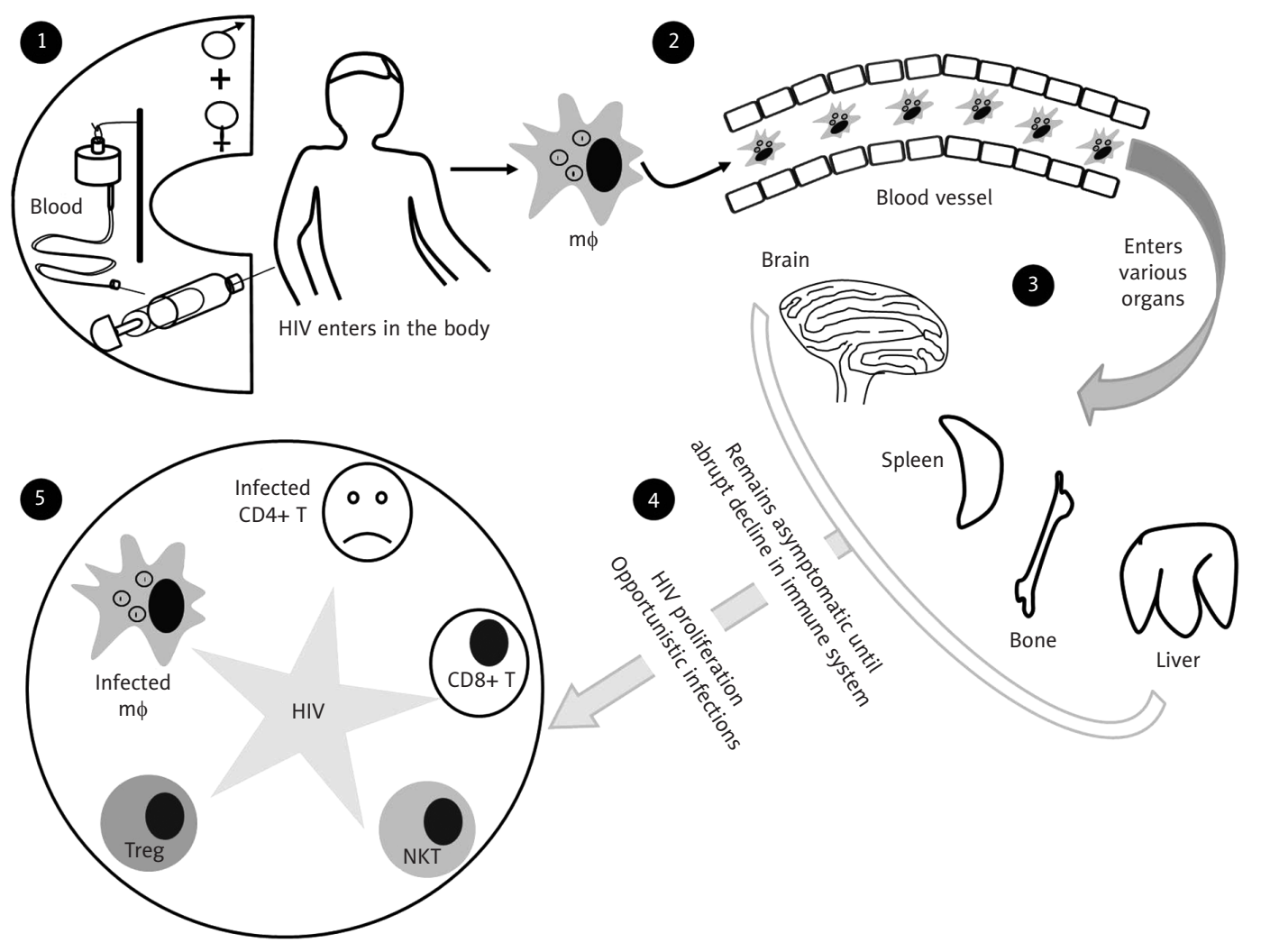

Figure 1. Schematic representation of HIV infection and its progression. 1. Showing limited routes of HIV infection to humans. 2. Virus first enters in the antigen presenting cells including macrophages $(m \varphi)$. 3. Infected $m \varphi$ travel all along the body, gets captured and/or preferentially recruited to various organs and spread the infection. 4. Virus and host's immunity attains an equilibrium and infections remain asymptomatic unless there is any abrupt decline in the host's immunity. 5. Schematic depictions of the cellular frontier(s) involved in the containment/dissemination of the virus 
cluding alveolar macrophages, rapidly proliferates and moves to some unreachable sites like brain using these highly mobile cells as vehicle [37]. Eventual loss of CD4+ $\mathrm{T}$ cells [38], elevated levels of suppressor of cytokine signalling (SOCS-1) [39], decreased IL-12p40 [40], elevated levels of IL-10 [41, 42], decreased IFNs mediated response [43-45] etc., were observed among infected individuals. In turn, the loss of potent CD4+ T cells driven immune response, favors the reactivation of latent TB infection [46, 47]. Besides the lack of CD4+ T cells, selective suppression of CD8+ T cells facilitates the M. tuberculosis to come out of immune containment. Programmed death-1 (PD-1) and $\mathrm{T}$ cell immunoglobulin and mucin receptor domain-3 (Tim-3), best known examples of receptors (marker of exhaustion), are shown to be upregulated on antigen specific CD8+ T cells. Virus driven manipulation of Th- 1 and Th-2 imbalance skews the immune response towards anti-inflammatory, and thus favors the dissemination of M. tuberculosis pathogen [48]. One of the hallmarks of tuberculosis is formation of granuloma, which contains the bacilli in the center surrounded by orchestrated layers of immune cells like $m \varphi$, T cells, granulocytes etc. In case of co-infection, HIV perturbs the granuloma formation and is characterized by diffused necrotic granuloma, not caseous granuloma, which is signature of TB [49]. Despite a robust Th-1 immune response, modulation of selected immune components may lead to reactivation of latent $M$. tuberculosis infection. Such immune components include Th-1/Th-2 imbalance [48], increased regulatory $\mathrm{T}$ (Treg) cells (defined by IL-10 producing FoxP3 positivity) [50-53], heightened level of TGF- $\beta$ [54], and IL-10 [42], decreased level of IFN- $\gamma$ [55] etc. It is now established that HIV triggers several of the above mentioned immune factors and compromises/impairs the anti-TB immune response [52]. Thus, M. tuberculosis disseminates to multiple organs that shows absence orchestrated granuloma. All forms of extra-pulmonary TB are reported in HIV-TB co-infection. Progression of TB also varies in different stages of HIV infection (full blown $>$ symptomatic $>$ asymptomatic) [56]. Though, several Th-1 skewed immune functions were severely compromised in full blown AIDS, but their dysfunctions often appear in asymptomatic cases as well $[52,57]$.

\section{Sentinels of immune system}

Immunologically, HIV infection is characterized by the imbalance in the proportions of immune cells, particularly because of selective depletion of CD4+ cells [58]. As CD4+ T cells are one of the frontrunners of ongoing immune response, its absence leads to a state of compromised immunity among HIV infected host [18]. Among the compromised hosts, the acquisition of new infection of tuberculosis and/or progression of disease from LTBI cases is especially high. It signifies the relevance of immune system and its components in keeping the protective mechanism(s) intact [59-62]. Here, we discuss the major components of immune system particularly in context to HIV and OIs.

\section{T cells}

Effector $\mathrm{T}$ cells against the pathogen are represented by two functionally and developmentally distinct subsets, $\mathrm{T}(\mathrm{CD} 4+)$ helper (Th) and $\mathrm{T}(\mathrm{CD} 8+)$ cytotoxic (Tc) cells. Functionally mature helper $\mathrm{T}$ cells are of two types, namely Th- 1 and Th- 2 . Th- 1 cells preferentially produce IFN- $\gamma$, IL-2 and TNF- $\alpha$ to stimulate the cell mediated immunity, which is crucial for containment of OIs particularly chronic intracellular pathogens like M. tuberculosis. On the other hand, Th- 2 cells are biased to produce more of IL-4, IL-13, and IL-10 etc., and boost the antibody production and suppress the Th-1 like immunity. The importance of Th-1/Th-2 paradigm has been studied in HIV infection [63]. To address the issue of Th-1/Th-2 paradigm in HIV, investigators focused attention to the cytokine producing cell, particularly the $\mathrm{T}$ cells derived from the disease site. HIV infection is characterized by the selective decline in CD4+ cells, leading to perturbed ratio of CD4 : CD8 T cells, which in turn compromises many essential function(s) of host immunity.

A state of compromised immunity fails to mount sufficient immune response and the host becomes significantly vulnerable to $M$. tuberculosis infection. To mount an effective immune response against the invaders, every arm of the immune system needs to be essentially intact, in particular CD4+ T cells. Furthermore, the selective vulnerability of CD4+ T cells to HIV infection could be one possible reason for inefficacy of many candidate therapeutic vaccines in trials, though they showed promising results in vitro. It is further compounded by the observation, which suggests selective down-regulation of MHC class II by Nef protein, indicating suppression of function of remnants CD4+ T cells, particularly in symptomatic cases progressing towards AIDS [64-66]. Without assistance of CD4+ T cells, CD8+ T cells remain incapable of inhibiting HIV progression and mounting strong immune response against $M$. $t u$ berculosis infection. It is evident from the findings, which show insufficient number of HIV specific CD8+ T cells in patients (progressor) than controls (non-progressor) [67]. A strong correlation is also observed between the activation of CD8 T cells and plasma viral load, suggesting crucial role of CD8+ T cells in containment of viral progression $[68,69]$. Many studies were undertaken, where HIV specific peptides in association MHC class I protein are used to prime and activate the CD8+ T cells and generate clones of HIV specific CD8+ T cells [70]. Data emanating from these recent studies indicate a possible suppression in the priming and activation of CD8+ T cells, possibly due to absence of CD4+ T cells, as evident by the impaired NFAT translocation [71]. Though, direct effects of HIV on CD8+ population and its function(s) are also reported. HIV is known to manipulate the expression of MHC class I using Nef expression and in turn evade the CTL response $[72,73]$. Nef is also known to downregulate the expression of CD80 and CD86 on infected cells, which leads to defective priming, activation, and further the function of CD8+ CTL cells [66]. Selective evasion from CD8+ CTL response favors not only the progression of HIV 
within host, but is also a major driving force for the evolution of global HIV-TB.

Therapeutically, protective CD8+ CTL responses have yet to be achieved by vaccine approaches for HIV-1 and M. tuberculosis infection. Measurement of frequency of HIV specific CD8+ cells and its restoration might be a good tool to evaluate the vaccine efficacy. New paradigms for generating effective CD8+ T cell responses against HIV-1/AIDS are required. These observations may have implications in vaccine development and protection from M. tuberculosis reactivation. Furthermore, out of 9 proteins of HIV available for vaccination, the early proteins Tat, Rev, and Nef may be better CD8+ T cell targets than the late-expressed structural proteins Gag, Pol, and Env [74-77]. It is also believed that CD8+ T cells directed against these early expressed proteins may be able to catch the infected cells prior to the establishment of disease. Few of these proteins have been tested and found to be potential enough to activate CD8+ T cells [75]. A cocktail vaccine may be tested for a possible vaccine in term of better activation of CD8+ T cells.

\section{B cells}

It is a general belief that the B cells and antibody may not have any significant role in preventing intracellular infection(s) like HIV and TB. However, the current trends are potentially supporting their role in protection, if not completely then partially. B cells, the antibody producing cells and a professional antigen presenting cells (APCs), may present antigen via MHC class I and II to CD8+ and CD4+ T cells, respectively [78-80]. Since the B cells are not directly infected with HIV virus, B cell mediated activation of CD8+ $\mathrm{T}$ cells are less likely to happen, except the cross presentation of exocytic antigens via MHC class I to CD8+ T cells [80]. Though, transmission of opsonized HIV to T cells via $B$ cells is reported [81]. Interestingly, Phuah et al. (2012) shows presence of activated $\mathrm{B}$ cells in the granulomas of nonhuman primates infected with M. tuberculosis [82]. Therefore, a detailed analysis would be required to understand the role of B cells in HIV-TB co-infection.

The neutralizing antibodies produced by long lived memory B cells have shown immune potential for regulation of acute HIV infection [83, 84]. Many neutralizing antibodies like HJ16, HGN194, HK20 [85], CH01, and VRC [86] have been identified and shown promising results. Antibody against gp41 has also been found to have immense potential [83]. It is also demonstrated that envelop protein of HIV stimulates the antibody production from B cells [87, 88]. However, neutralizing antibodies are less durable and having broad specificity but narrow effectiveness [29, 83, 89]. The acute phase of HIV infection is characterized by the hyper activation of $\mathrm{B}$ cells, production of non-protective antibody mainly against the envelop protein [90]. Though in chronic HIV infection, where persistent encounter with the antigens occurs, B cells shows high PD-1, low BTLA, decreased proliferation (Ki67+), and antibody production, suggesting overall dysfunction of B cells $[50,91]$. Expression of PD-1 is correlated with the CD4 count, total antibody production, and total viral load [92-95]. It is reported that the blocking of PD-1 pathway may revert the dysfunctional antibody response during HIV-1 infection [96]. To add here, the HAART gradually improves the frequency and function of B cells with the decrease in viral load.

The absence of help from CD4+ T cells could be a reason for the dysfunctional state among B cells in chronic HIV infection. Class switching from IgM $\rightarrow$ IgG $\rightarrow$ IgA and affinity maturation is required for anti-viral immunity by constantly enriching the effective antibody repertoire $[97,98]$. These processes are result of interaction between $\mathrm{B}$ cells expressing CD40 and CD4+ T cells expressing CD40L. Selective depletion of CD4+ T cells and in turn absence of CD40-40L signalling, firstly suppresses these critical processes within $\mathrm{B}$ cells, resulting in poor repertoire of antibody producing cells. Secondly, it does not trigger the B cells to produce C-C chemokines like RANTES and MIP-1 $\alpha$ required for inhibition of HIV [99, 100].

Approaches are being laid to develop the antibody based serological diagnosis of HIV-TB co-infection cases. In such cases, antibody response against protein antigen is reported to be poor [101, 102]. Though, the antibody response against glycolipids are found to be sensitive, and $22.7 \%$ of HIV infected patients showed asymptomatic development of antibody against M. tuberculosis infection. However, no correlation was observed between the level of antibody and progression into active disease. It is interesting to note that the antibody production to glycolipids was higher in sera from HIV-positive as compared to HIV-negative TB patients [103]. This might be due to non-classical mode of presentation of glycolipid antigens, possibly requires little assistance from CD4+ T cells. The function of B cells in protection against TB still needs an exploration. However, their potential in M. tuberculosis infection is thought to be underestimated. A strong antibody response against glycolipid, if not protein antigens, could be helpful in capturing bacterial antigen, making it available to phagocytes, and thus modulating the cellular immune response through innate immune cells like natural killer T (NKT) cells [103]. Importantly, an antibody response results in opsonization of extracellular bacilli, limiting its dissemination to other sites.

\section{Macrophages}

Besides CD4+ T cells, tissue macrophages $(\mathrm{m} \varphi)$ and/ or its precursor monocytes are one of the two important harboring host cells, where virus enters, resides, integrates, and replicates. Importantly, $\mathrm{m} \varphi$ is the site, which also harbors $M$. tuberculosis bacilli. Depending on host cell types either CD4+T cells or $\mathrm{m} \varphi$, viruses are termed as $\mathrm{T}$ tropic or $M$ tropic, respectively. Due to limited life span of $m \varphi$, it is believed that long lived CD4+ memory cells, but not the $m \varphi$, are the cells where the virus persists and re-appear in future [36]. Though, $m \varphi$ helps them to evade the killing effect of HAART, by harboring them and moving to an inaccessible site, where immune onslaught may not happen i.e., 
immune privilege site. Later, $m \varphi$ infected with HIV forms long intercellular conduits and allows safe passage of the viruses to other lymphocytes [104]. HIV-1 selectively depletes, not only CD4+ T cells, but Kupffer cells ( $\mathrm{m} \varphi$ in liver), which gets recovered after HAART [105]. Many proteins expressed by HIV i.e., Nef, Gag, Tat, and Env suppresses the function of $\mathrm{m} \varphi$ by various means, and provides the permissive atmosphere for HIV replication. Since HIV as well as M. tuberculosis bacilli both are present in $\mathrm{m} \varphi$, it seems unavoidable to have cross talk in their evasion mechanism(s). Thus, HIV offers a favorable immunologically compromised environment to bacilli, and in return bacilli promotes the replication of virus. Specifically, HIV impairs the TNF- $\alpha$ mediated apoptosis of $\mathrm{m} \varphi$, and thus facilitates the survival of bacilli. Moreover, HIV disintegrates the granuloma organization leading to dissemination of bacilli [49].

HIV-1 is known to impair the function(s) of $m \varphi$ like phagocytosis [106], decreased sensitivity towards cytokines [107], and response to pathogen associated molecular patterns (PAMPs) [108], etc. It has been shown that many inhibitory molecules like suppressor of cytokine signalling 1 and 3 (SOCS1 and SOCS3) are increased in response to HIV infection, and suppresses the effectiveness of IFNs by modulating the phosphorylation of STATs [108, 109]. HIV also modulates the expression of MHC class I and II [64, 110], resulting in impaired CD8+ and CD4+ T cells response, respectively. It is also demonstrated that the immunological synapse between T cells and HIV infected $m \varphi$ are not disrupted [111]; though, there is significant reduction in the expression of MHC and co-stimulatory molecules (CD80/86) $[110,112]$. Mycobacterium tuberculosis bacilli inhibit the fusion of phagosome and lysosome, and survives in the $m \varphi$. In HIV manipulated $m \varphi$, lack of IFN- $\gamma$ triggered oxidative burst supports the survival of bacilli. Moreover, elevated serum level of IL-10 in HIV infected patients is also thought to be involved in suppression of $\mathrm{m} \varphi$ supporting growth of $M$. tuberculosis infection $[113,114]$.

Till date, to the best of our knowledge, approaches of vaccine development based on acquired immunity have failed, resulting in surge of exploring new pathways of immune activation. Innate activation of immune system mounts an efficient response, challenging the invaders without recognizing them (non-specific). HIV also encodes many molecules (e.g., ssRNA), which may serve as potential PAMPs, and may be recognized by the pathogen recognition receptor (PRR) expressed by $m \varphi$ and other cells (e.g., TLR7/8) [115-117]. Such interaction leads to prior activation of cells [118]. Thus, these pre-activated cells encounter the virus and significantly delay their progress. For an example, TLR-4 ligand suppresses the HIV-1 replication in $\operatorname{m} \varphi[119,120]$. To utilize the non-specific nature of innate immune activation, co-infection with commensal bacteria and parasite e.g., Trypanosoma cruzi inhibits the replication of HIV-1 within $\mathrm{m} \varphi$. These organisms express many PAMPs, which triggers various TLRs on the surface/endocytic vesicles in MyD88 dependent manner [119-122]. However, HIV is known to inhibit TLR signalling by down-regulating IRAK-4 involved in downstream signalling [123]. Suppression of TLR signalling in HIV infected $m \varphi$ facilitates the impaired detection of $M$. tuberculosis bacilli [52].

Functional commitment of $\mathrm{m} \varphi$ depending on its capacity to produce IL-12 (M1) and IL-10 (M2) may be a relevant area to be explored $[124,125]$. It would also be interesting to see how HIV modulates the balance of M1 and M2 in their favor. Moreover, how immune system maintain their balance to keep the protection intact is not still clear. It is conclusively reported that IL-10 is significantly produced among patients (progressor) as compared to controls (non-progressor) [41]. Besides regulatory T cells [126, 127], M2 type $\mathrm{m} \varphi$ are one of the dominant producer of IL-10. However, it is shown that HIV-1 does not alter in vitro and in vivo IL-10 production by human monocytes and macrophages [128]. Recent studies suggest that encouraging the M1 type function of $m \varphi$ may help in restoration of protective mechanisms among HIV infected patients [129].

\section{Cytokines}

Production of cytokines following TLRs induced activation of macrophages is important for immunity to HIV. Several cytokines are released, some of which take part in non-specific inflammation, and others regulate the functional bias of the relevant T cells. An account of the important cytokines produced upon HIV infection and their roles is given here and in other sections as well. These cytokines eventually induce further activation of immune cells and lead to a complex process of immune regulation. Among the cytokines, tumor necrosis factor- $\alpha$ (TNF- $\alpha$ ), IFN- $\gamma$, IL-1 $\beta$, IL-6, IL-12, IL-10, IL-4, and TGF- $\beta$ are important. Each of them plays distinct role in the immune response against TB.

Briefly, pro-inflammatory cytokines like TNF- $\alpha$, IFN- $\gamma$, IL-1 $\beta$, IL-6, and IL-12 plays key roles in macrophage activation, immuno-regulation, and particularly granuloma formation by induction of appropriate chemokine receptors on the effector $\mathrm{T}$ cells, and thus recruiting them at the site of pathology. However, it is thought to be a "double edged sword" causing bystander damage of the host tissue and cavity formation, particularly when present in relative excess in the milieu. In addition to the production of the above pro-inflammatory cytokines, certain anti-inflammatory cytokines are produced as well in HIV infection. Some of these, such as IL-4, IL-10, and TGF- $\beta$ are Th-2 like cytokines and their role in the immuno-pathogenesis of AIDS has provided the concept of Th-1/Th-2 paradigm in various forms of TB. These cytokines are believed to antagonize the protective and/or containing immunity, thus suppressing the required immunity.

Th-1 responses and dendritic cell (DC) functions are compromised in HIV-1 infected individuals. DCs induce elevated levels of SOCS-1, and secrete decreased IL-12 and elevated levels of IL-10, following TLR-4 stimulation by LPS [41]. Similar to TGF- $\beta$ [54], IL-10 suppresses the virus specific $\mathrm{T}$ cell function in SOCS dependent manner, and IL-10 producing cells define a suppressive population among HIV infected host [126]. Skewed Th-1/Th-2 balance, where IL-4/ 
IL-13 are dominantly tilt the balance towards Th- 2 and cytokine(s) like IL-10 and TGF- $\beta$ suppresses the Th- 1 functions, are responsible for the breakdown of latency and dissemination of disease.

\section{Chemokines}

Briefly, chemokines are small size chemo-attractants, involved in preferential trafficking of inflammatory cells [130]. Since the chemokine's receptors serve as co-receptor for viral entry, the role of chemokines has become interesting to explore. It is observed that the increase in plasma load of HIV-1 coincided with massive burst in the chemokine expression. Importantly, IP-10, MCP-1, IL-8 etc., were found to be increased in the periphery of HIV infected individuals [131134]. The heightened levels of chemokines are believed to cause immune activation, followed by viral replication, and thereafter more destruction of CD4+ T cells. It is believed that the early virus used only CCR5, and later evolved and started using CCR5 and CXCR4 both as co-receptor [135-137]. One more step ahead, HIV-1 is gradually acquiring resistance to CCR5 ligands most notably RANTES, resulting in increased virulence [138]. CCR5 and CXCR4 expression did not differ significantly between HIV patients with and without tuberculosis $[139,140]$. Moreover, RANTES controls the dissemination of the virus as well as the M. tuberculosis bacilli in vitro and in vivo [141], and acquisition of anti-RANTES resistance will breach critical immune gateways leading to uncontrolled expansion of virus. Not only RANTES, but other ligands of CCR5 (MIP-1 $\alpha$ and $\beta$ ) also suppress the expansion of virus in vivo [142]. Mycobacterium tuberculosis infection increases the CCR5 expression (co-receptor for HIV entrance) as well as decreases the level of RANTES, and thus facilitates the HIV infection [141, 143-145]. Prophylactically, a lentivirus construct of RANTES with another protein (KDEL), which help in its retention within endoplasmic reticulum (ER), showed $\sim 50-60 \%$ reduction in HIV (DP1, a R5 strain) infection [146].

\section{Orchestration of cellular immune response against HIV}

The progression of HIV infection is hallmarked by acute viremia in very early days, followed by steep rise in the frequency of peptide specific CD8+ (CTL) T cells [147]. The peptide/epitope specific CD8+ T cells are measured using a multimeric HLA tetramer carrying peptide and streptavidin detection system [148]. Such advancement has eased the measurement of the immune response mounted by host $[149,150]$. Immediately after reaching at the peak, virus declines in number and it is followed by decrease in the HIV specific CD8+ T cells [147] (Figure 2). When the virus gets reduced quantitatively, $\mathrm{CD} 8+\mathrm{T}$ cells fail to survive and undergo apoptosis rapidly, suggesting that the presence of antigen is required for the maintenance of antigen specific CD8+ CTL cells [151]. Actually, the primed CD8+ T cells tend to expand in the presence of specific antigen of HIV.

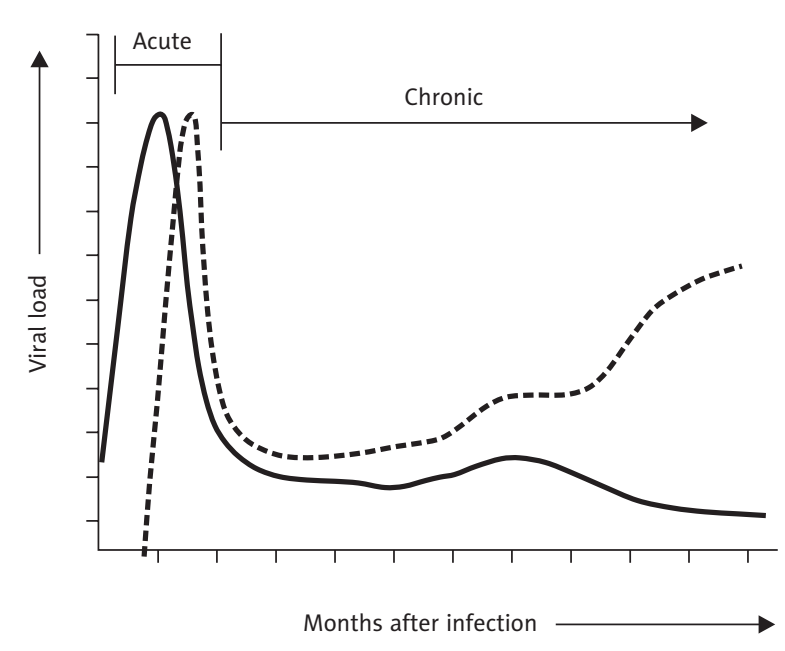

Figure 2. Diagrammatic representation of the interrelationship between viral load (solid line) and antigen specific CD8+ $T$ cells (dotted line). In the acute phase, the steep rise in the viral load is followed by the surge in antigen specific CD8+ $T$ cells. When the treatment is instituted, there is decline in the viral load followed by CD8+ T cells and reaches to a state of equilibrium

These expanded CD8+ T cells kill the virus infected cells by inducing apoptosis and it is mediated by the molecules either expressed on the surface (FASL, PD-L1/L2 etc.), and/ or secreted (perforin, granzyme etc.) in close vicinity to the target cells $[93,152,153]$. This may also be mediated by the cytokine(s) (IFN- $\gamma$, TNF- $\alpha$ etc.) released by CD $8+$ CTL cells [154]. It is not yet clear, which function of CD8+ CTL cells are most important in controlling the HIV.

For the maintenance of virus specific CD8+ T cells and its revival whenever required, a small fraction of primed CD8+ T cells will be stored as long lived memory T cells, and maintain the repertoire of each epitope specific CD8+ (CTL) $\mathrm{T}$ cells [155]. It is also required because if each epitope specific CD8+ T cells enters into effector phase, and at one stage all will get exhausted and immune response will be dampened off. These epitopes specific CTL cells do perform, and on the other hand, get manipulated by the virus by impairing the expression of MHC class I and other co-stimulatory molecules $[66,112]$. Though, by measuring epitope specific CD8+ T cells using peptide MHC tetramer staining, it helps in numerically identify these cells, but do not assign their functional behavior. A co-staining of peptide MHC tetramer and the cytokines/perforin/granzyme at the intracellular level helps to functionally characterize them. When such co-staining was performed, it was found that HIV specific CD8+ T (Tetramer+) cells produced cytokines i.e., IFN- $\gamma$, TNF- $\alpha$ etc. upon stimulation with cognate antigen, but significantly failed to produce perforin/granzyme as compared to CMV specific cells $[153,156]$.

Recent studies have changed the standing concept of this field. Earlier, it was believed that the HIV specific CD8+T (CTL) cells may be less efficient (less perforin), 


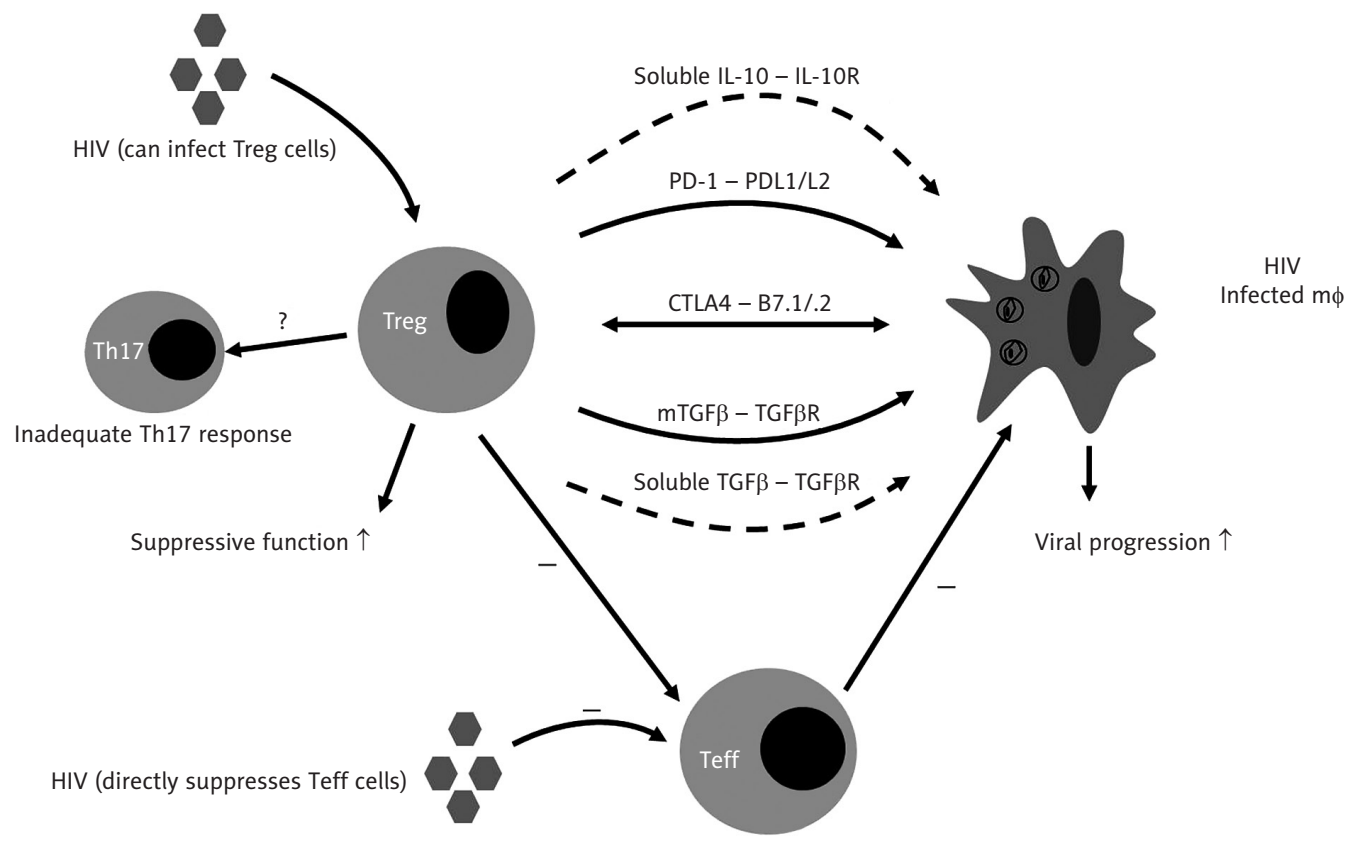

Figure 3. HIV triggered suppression of immune response. HIV infects macrophages and T cells, suppresses the anti-HIV immunity, and in-turn increases the viral replication. Another player, regulatory $T$ cells, can suppress the immune response by inhibiting macrophage and Teff cells in contact dependent and/or contact independent

but get primed, matures, and perform effector function(s). A comparative analysis of HIV specific and CMV specific CD8+ cells showed that HIV specific CD8+ T cells were CD27+CCR7-CD45RA-compared to CMV specific CD8+ $\mathrm{T}$ cells (CD27-CCR7-CD45RA+), suggesting faulty maturation of CD8+ T cells among HIV infected host $[153,156]$. This seems obvious in absence of CD4+ T cells help. CD8+ $\mathrm{T}$ cells act best within a limited window period from infection of new cells to release of viruses. CD8+ T cells are generally very effective in their function, otherwise, virus escapes the killing cells by applying various mechanism(s) e.g. downregulation of MHC class I on host cells and remain undetectable to CD8+ T cell etc. Simultaneously, before getting eliminated by $\mathrm{CD} 8+\mathrm{T}$ cells, the virus puts a selection pressure and evolves a mutant, which is not recognized by effector CD8+ cells, giving additional advantage to the mutant infected cells. It becomes even harder for the immune system to take control of the progression of rapidly evolving mutant, as there is no phenomenon like 'affinity maturation' in TCR among CD8+ T cells.

Various non-classical subsets of fine $\mathrm{T}$ cells bear non-conventional $\mathrm{T}$ cell receptors (TCRs) or do not recognize the antigens in context of major histocompatibility (MHC) molecules and exert an immunoregulatory influence on the conventional $\mathrm{T}$ cells (expressing $\alpha \beta \mathrm{TCR}$ ) including the effector $\mathrm{T}$ cells. Important among them and worth mentioning are $\gamma \delta$ T cells (expressing $\gamma \delta$ TCR and recog- nize antigen in non-MHC manner), NKT cells (recognize antigen in context to CD1 molecules), and the regulatory T cells (Treg). In HIV infection, the frequency of $\gamma \delta$ T cells is decreased and show impaired production of cytokine like IFN- $\gamma$ and TNF- $\alpha[157,158]$. Though, the findings are contradictory $[159,160]$, but the immense potential of $\gamma \delta$ T cells are always appreciated. Another subset, NKT cells represent a subset of $\mathrm{T}$ cells with a distinct lineage, not restricted by $\mathrm{MHC}$ and can be divided into diverse/variant and invariant NKT cells [161]. They recognize lipid antigens in context to relatively less polymorphic CD1 molecules. CD1 molecules are sub-grouped into group I consisting of CDla, b, c, and e, whereas CD1d is the only member of group II so far known. CD1d restricted invariant NKT cells are heterogeneous in terms of their expression of CD4/CD8 markers, and an important subset of NKT cells uses restricted set of TCR chain pairs $[161,162]$. NKT cells are one of the earliest T cells to be triggered in an immune response. NKT cells might play a role in HIV-1 infection, and therefore be selectively depleted during the early stages of infection [163]. Recent studies are reviewed regarding the dynamics of NKT depletion during HIV-1 infection and their recovery under HAART [164]. It is also demonstrated that HIV possibly manipulates the function of NKT cells by downregulating expression of CD1d [165]. NKT cells including $\gamma \delta$ T cells are the early innate players regulating the onset of anti-HIV immune response. 
Another factor, regulatory $\mathrm{T}$ (Treg) cells are a subpopulation of CD4+ T cells characterized by the suppressive effect they mount on the HIV specific immune responses [166, 167]. Similar to CD4+ effector T cells, Treg cells are equally susceptible to HIV, and may also get infected with HIV through CD4-gp120 interaction with its suppressive function getting increased [168]. Treg cells suppress the other cells either by contact dependent and/or contact independent. Contact dependent suppression includes following mechanisms i.e., PD1-PDL1/L2, CTLA4-B7.1/7.2, mTGF $\beta$-TGF $\beta R$, GITR, IDO, HLA-G etc. [53, 169]. The contact of independent pathways is mostly IL-10-IL-10R, sTGF $\beta$-TGF $\beta$ R, CD39$\mathrm{CD} 73 \rightarrow$ adenosine etc. Interesting to note that the frequency of Treg cells (CD4+CD25+FoxP3+) cells are significantly increased among HIV infected individuals [51], and are having activated phenotype $[127,170]$. Furthermore, the expression of PD-1 is upregulated on Treg cells and significantly correlated with the HIV progression $[169,171]$. The production of IL-10 was increased among infected individuals and Treg cells are found to be one of the dominant producers of IL-10 [41, 42, 54, 128, 172-174] (Figure 3). Increased level of IL-10 producing Treg cells offers a conducive platform form reactivation of latent $\mathrm{TB}$ infection and its progression in disseminated form of TB [175-178]. It is also demonstrated that the blocking of IL-10 with anti-IL-10 Ab restores the effector immune response. Recent studies suggest that the blocking Treg cells or its key function(s) may be a viable option in controlling viral progression.

\section{Immunosuppression}

Immunosuppression among HIV infected individuals as a result of gradual loss of CD4+ T cells, dysfunction of CD8+ T cells, and ineffective antibody response by B cells, may lead to uninterrupted progression of virus and open invitation to deadly $M$. tuberculosis infection [179]. Depending on the possible causes, the immunosuppression may also be categorized. In case of HIV, the foremost cause of immunosuppression is the virus mediated suppression of immune recognition, selective loss of CD4+ T cells etc. The other type of immunosuppression such as OIs, chemotherapy, and malnutrition etc., is common in countries like India [180-182].

One very important factor is the host genetic makeup, providing background, which may already be predisposed to get suppressed. Mostly, highly polymorphic human leukocyte antigens (HLA) play significant role in deciding that which part of antigen will be presented in what orientation. An antigen mostly contains more than one epitope. One epitope is used by HLA/MHC for presentation of peptide (antigen) and the other epitope is recognized by the T cell receptor (TCR). It is always HLA having upper hand in choosing the right epitope to bind with and present to T cells. When an HLA molecule first binds with a peptide (antigen), it undergoes peptide sorting and chooses the best combination of HLA and epitope (Figure 4). The allelic composition of HLA at gene level decides the strength and accuracy of peptide presentation, and thus the immune response.

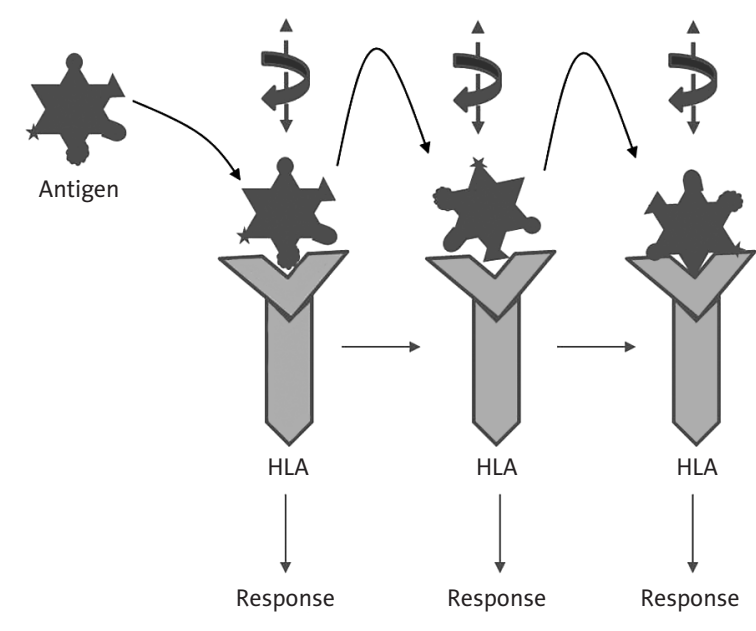

Figure 4. Interaction between HLA and antigen. Antigen bearing multiple epitopes gets oriented in different ways to best fit with HLA. HLA itself binds with one epitope having optimum affinity and displays highly immunogenic epitopes to $T$ cell receptor (TCR)

Supporting to the above said, HIV-1-infected persons with HLA-B27 and -B57 alleles commonly remain healthy for decades without antiretroviral therapy [183]. Oppositely, many allelic combinations of HLA gene among host are proven immunosuppressive and generate poor immune response [184]. Besides HLA polymorphism, polymorphism among cytokines, chemokines, their receptors and PRRs (TLRs etc.) have been studied and demonstrated that few single nucleotide mutations led to low producer of protective cytokines [185-187]. Except few, none of the studies conclusively suggest anything.

Immunosuppression, in general, a multifactorial phenomenon leading to compromised immunity. Prior genetic predisposition, Treg cells, increased IL-10, inadequate Th-17 response, more IL-4 producing NKT (NKT2) cells, perturbed ratio of Th-1 vs. Th-2, deficiency of critical nutrients (vitamins etc.) etc. are involved, one way or other, in immunosuppression. HIV itself and/or chemotherapy induces immunosuppression and make the atmosphere conducive for OIs and allow them to flourish [188, 189].

\section{Reactivation of latent tuberculosis infection worsening the management of HIV}

Opportunistic infections are the major risk factor in AIDS group of patients (CD4 counts $<250$ cells $/ \mathrm{mm}^{3}$ ). Approximately, $80 \%$ of deaths are due to OIs. Various pathogens ranging from protozoan, fungal, bacterial to viruses infect such compromised host with great ease [190]. These pathogens first of all, do not get potential encounter from the host immune system, and a small inoculum may be sufficient to 
establish the co-infection. A compromised immunity among patients undergoing crisis phase (abrupt break down of immune system; CD4 count $<250$ cells $/ \mathrm{mm}^{3}$ ) attract some of the deadliest pathogen $[179,185]$. The significance of immune system is clearly visible from the data of developed country including America, where there is emergence in new cases of $\mathrm{Tb}$ along with resurgence in LTBI. In developing country like India, where the unhygienic conditions embrace various infections, health management of the AIDS patients are extremely difficult task $[179,191,192]$. On top of this, the M. tuberculosis infection may in turn trigger the breakdown of latency or prophase stage of the HIV virus, leading to abrupt increase in viral load followed by steep decline in CD4 counts [190, 193].

All individuals infected with HIV are susceptible to a wide array of OIs, in addition to infections that are pathogenic to hosts without HIV infection. Tuberculosis is the commonest opportunistic infection and the number one cause of death in HIV/AIDS patients in developing countries. Co-infection of a progressed HIV infected host with Mycobacteria sp. generally causes reactivation, and then disseminated form of disease, affecting many critical and vital organs. It is estimated that one-third of the world's population is infected with $M$. tuberculosis. However, we fail to find any authentic approach to this estimation. However, the risk of developing TB is reduced by $70-90 \%$ among patients receiving antiretroviral therapy. Despite therapy and continuous monitoring such co-infections, result in devastating outcome. Amongst the varied spectrum of the disease, pulmonary tuberculosis (PTB) is still the commonest form of TB in HIV infected patients. A major fraction of them later turn up as extremely drug resistant (XDR). On the other hand, M. tuberculosis infection enhances replication of HIV-1 and progression to AIDS [194]. It suggests that besides the immunosuppression caused by HIV, the immune system is additionally suppressed by $M$. tuberculosis infection, resulting in abrupt decline in immunity and progression of virus.

HIV infection continues to be a lethal disorder characterized by opportunistic infection with uncommon organisms (e.g., mycobacteria, fungi, parasites, and viruses), as well as lethal malignancies. Opportunistic infections may also be categorized into acute vs. chronic depending on their course of progression in HIV infected host. Acute OIs like active TB, acute hepatitis $\mathrm{C}$ virus (HCV), chickenpox virus, bacterial infection (egg. pneumocystis) etc., requires critical attention for the management, as the disease progresses and/or disseminates extremely faster [12]. The M. tuberculosis agents causing acute cytopathy can kill the cells in host, if the immune response doesn't comes up within 3-7 days. Compromised immunity among HIV infected host led to devastating outcome upon reactivation of M. tuberculosis infection from latent to active. Initiation of therapy results in equilibrium between immune response and acute cytopathic effect caused by infectious agents. Fungal infections like oropharyngeal candidiasis are the commonest opportunistic infections among AIDS patients and further worsen the disease management of HIV-TB cases. However, under condi- tions of immune dysfunction, colonizing Candida albicans can even trigger life-threatening infections, which otherwise remain superficial $[195,196]$.

It has always been tedious to understand about the treatment among co-infected patients. Once HAART is initiated, it should not be stopped if OIs appears. HIV-positive patients not on ART with sputum smear positive TB can start anti-TB treatment (ATT). However, any HIV-positive patient with TB who is already on ART, must be assessed before subjecting them to ATT. The recent WHO treatment guideline (2015) recommends early antiretroviral and/or early isoniazid prophylaxis therapy against $M$. tuberculosis infected HIV positive adults, regardless of CD4 count [197]. Study showed that concurrent administration of ART with TB treatment improves the treatment success rates and low fatality. Trial conducted compared the efficacy of co-administration of ATT with HAART and found favorable outcome. The 2015 WHO guidelines recommend oral pre-exposure prophylaxis (PrEP) for high risk population (more than 3\% HIV incidence). However, its efficacy among drug resistant infections must be validated [197].

Nevertheless, there are many problems associated with this like combined drug toxicities, drug - drug interactions, immune reconstitution inflammatory syndrome (IRIS). Even if there is concern of drug related toxicity, HAART should not be withheld from co-infected patients. Co-infected patients with reduced CD4-cell counts should unhesitatingly be first subjected to HAART. Importantly, early initiation of antiretroviral therapy in TEMPRANO and START (strategic timing of antiretroviral therapy) trials showed superior in preventing sever AIDS related problems with no adverse effect, and was associated with lower risk of death [197]. After commencement of HAART, immune reconstitution inflammatory syndrome (IRIS) frequently appears and this results in clinical deterioration with inflammatory illness among patients experiencing immune recovery during early HAART [198]. A detailed study should be undertaken to decipher the effects associated with IRIS.

\section{Conclusions}

It was disappointing to find poor performance of sputum smear microscopy in HIV-infected patients suggesting the need of another reliable technique for detecting co-existence of both bacilli and virus [101, 102, 199]. Leading candidate vaccines for either of pathogen have not been effective. However, these studies are not conclusive and reported contrasting findings [200-204]. It has become a necessity to recalibrate many fine intricacies of the immune system that were not prioritized earlier. Immune system is significantly involved in dictating the overall defense of the body, as well as supporting the candidate vaccine to become effective. Suppression of the immune system has not been addressed before, as now it is being focused in last 5-7 years. Exploring various pathways involved in immunosuppression is required to pinpoint the root-cause of the problem. Furthermore, immunosuppression as such is multi-factors process 
and it has always been difficult to address one or two causes. Not only the pathogen, but the overall socioeconomic status of the infected individuals is involved in culpable growth of the co-infection. This is clearly visible between healthy and non-healthy individuals who accidently acquired the virus infection. Their capacity to contain the virus and remain asymptomatic for long varies drastically, and so as their capability to restrict the reactivation of the $M$. tuberculosis latent infection. An HIV infected but asymptomatic individual never undergoes reactivation of latent $M$. tuberculosis infection, unless there is abrupt decline in the immune system. So, to develop an efficacious way to target co-infection, a multidirectional approach resolving immunosuppression might be beneficial.

\section{Conflict of interest}

The author's declared no potential conflicts of interest with respect to the research, authorship, and/or publication of this article.

\section{References}

1. UNAIDS. Fact sheet, 2016, pp. 1-8. Available at: http://www.unaids. org/en/resources/fact-sheet.

2. Zeier MD. Targeting HIV: past, present and future. Infect Disord Drug Targets 2011; 11: 98-114.

3. Pacold M, Soto P. Retroviruses and opportunistic infections - 15th annual conference. IDrugs 2008; 11: 233-235.

4. Herrero MD, Rivas P, Rallon NI, et al. HIV and malaria. AIDS Rev 2007; 9: 88-98.

5. Borkow G, Bentwich Z. HIV and helminth co-infection: is deworming necessary? Parasite Immunol 2006; 28: 605-612.

6. Wilkinson KA, Schwander S, Torok ME, et al. Human immunodeficiency virus-associated tuberculosis. Clin Dev Immunol 2011; 2011: 513967.

7. Corti M, Palmero D, Eiguchi K. Respiratory infections in immunocompromised patients. Curr Opin Pulm Med 2009; 15: 209-217.

8. Ali A. Leishmaniases and HIV/AIDS co-infections: review of common features and management experiences. Ethiop Med J 2002; 40 Suppl 1: 37-49.

9. UNAIDS. Global AIDS Update 2016, 2016, pp. 1-12. Available at: http://www.unaids.org/en/resources/documents/2016/Global-AIDSupdate-2016

10. Verheggen R. Immune restoration in patients with HIV infection: HAART and beyond. J Assoc Nurses AIDS Care 2003; 14: 76-82.

11. Sedaghat AR, Rastegar DA, O’Connell KA, et al. T cell dynamics and the response to HAART in a cohort of HIV-1-infected elite suppressors. Clin Infect Dis 2009; 49: 1763-1766.

12. Feller L, Wood NH, Chikte UM, et al. Tuberculosis part 3: HIVtuberculosis co-infection. SADJ 2009; 64: 352-354.

13. Kalsdorf B, Scriba TJ, Wood K, et al. HIV-1 infection impairs the bronchoalveolar T-cell response to mycobacteria. Am J Respir Crit Care Med 2009; 180: 1262-1270.

14. Westreich D, MacPhail P, Van Rie A, et al. Effect of pulmonary tuberculosis on mortality in patients receiving HAART. AIDS 2009; 23: 707-715.

15. Lawn SD, Churchyard G. Epidemiology of HIV-associated tuberculosis. Curr Opin HIV AIDS 2009; 4: 325-333.

16. Martinson NA, Moultrie H, van Niekerk R, et al. HAART and risk of tuberculosis in $\mathrm{HIV}$-infected South African children: a multi-site retrospective cohort. Int J Tuberc Lung Dis 2009; 13: 862-867.
17. Pawlowski A, Sköld M, Rottenberg ME, et al. Tuberculosis and HIV co-infection. PLoS Pathog 2012; 8: e1002464.

18. Fernandez S, Lim A, French M. Immune activation and the pathogenesis of HIV disease: implications for therapy. J HIV Ther 2009; 14: 52-56.

19. Brainard DM, Seung E, Frahm N, et al. Induction of robust cellular and humoral virus-specific adaptive immune responses in human immunodeficiency virus-infected humanized BLT mice. J Virol 2009; 83: 7305-7321.

20. Galati D, Bocchino M. New insights on the perturbations of T cell cycle during HIV infection. Curr Med Chem 2007; 14: 1920-1924.

21. Sirois M, Robitaille L, Sasik R, et al. R5 and X4 HIV viruses differentially modulate host gene expression in resting CD4+ T cells. AIDS Res Hum Retroviruses 2008; 24: 485-493.

22. Coiras M, Lopez-Huertas MR, Perez-Olmeda M, et al. Understanding HIV-1 latency provides clues for the eradication of long-term reservoirs. Nat Rev Microbiol 2009; 7: 798-812.

23. Willard S, Holzemer WL, Wantland DJ, et al. Does "asymptomatic" mean without symptoms for those living with HIV infection? AIDS Care 2009; 21: 322-328.

24. Ford ES, Puronen CE, Sereti I. Immunopathogenesis of asymptomatic chronic HIV Infection: the calm before the storm. Curr Opin HIV AIDS 2009; 4: 206-214.

25. Huang MB, James CO, Powell MD, et al. Apoptotic peptides derived from HIV-1 Nef induce lymphocyte depletion in mice. Ethn Dis 2008; 18: S2-30-37.

26. Yates A, Stark J, Klein N, et al. Understanding the slow depletion of memory CD4+ T cells in HIV infection. PLoS Med 2007; 4: e177.

27. Tsong Fang HR, Colantonio AD, Uittenbogaart $\mathrm{CH}$. The role of the thymus in HIV infection: a 10-year perspective. AIDS 2008; 22: 171-184.

28. Getz WM. HIV dynamics and immunosenescence. AIDS 2008; 22: 307-309.

29. Tomaras GD, Haynes BF. HIV-1-specific antibody responses during acute and chronic HIV-1 infection. Curr Opin HIV AIDS 2009; 4: 373-379.

30. Maslin CL, Kedzierska K, Webster NL, et al. Transendothelial migration of monocytes: the underlying molecular mechanisms and consequences of HIV-1 infection. Curr HIV Res 2005; 3: 303-317.

31. Hasegawa A, Liu H, Ling B, et al. The level of monocyte turnover predicts disease progression in the macaque model of AIDS. Blood 2009; 114: 2917-2925.

32. Gorry PR, Sonza S, Kedzierska K, et al. Isolation of human immunodeficiency virus type 1 from peripheral blood monocytes. Methods Mol Biol 2005; 304: 25-33.

33. Ellery PJ, Crowe SM. Phenotypic characterization of blood monocytes from HIV-infected individuals. Methods Mol Biol 2005; 304 : 343-353.

34. Rao VR, Eugenin EA, Berman JW, et al. Methods to study monocyte migration induced by HIV-infected cells. Methods Mol Biol 2009; 485: 295-309.

35. Yadav A, Collman RG. CNS inflammation and macrophage/microglial biology associated with HIV-1 infection. J Neuroimmune Pharmacol 2009; 4: 430-447.

36. Alexaki A, Liu Y, Wigdahl B. Cellular reservoirs of HIV-1 and their role in viral persistence. Curr HIV Res 2008; 6: 388-400.

37. Wang H, Sun J, Goldstein H. Human immunodeficiency virus type 1 infection increases the in vivo capacity of peripheral monocytes to cross the blood-brain barrier into the brain and the in vivo sensitivity of the blood-brain barrier to disruption by lipopolysaccharide. J Virol 2008; 82: 7591-7600.

38. Douek DC, Roederer M, Koup RA. Emerging concepts in the immunopathogenesis of AIDS. Annu Rev Med 2009; 60: 471-484.

39. Song XT, Aldrich M, Chen SY. Suppressor of cytokine signalling 1 inhibition strategy to enhance anti-HIV vaccination. Expert Rev Vaccines 2006; 5: 495-503. 
40. Ma W, Mishra S, Gajanayaka N, et al. HIV-1 Nef inhibits lipopolysaccharide-induced IL-12p40 expression by inhibiting JNK-activated NFkappaB in human monocytic cells. J Biol Chem 2009; 284: 7578-7587.

41. Brockman MA, Kwon DS, Tighe DP, et al. IL-10 is up-regulated in multiple cell types during viremic HIV infection and reversibly inhibits virus-specific T cells. Blood 2009; 114: 346-356.

42. Elrefaei M, Ventura FL, Baker CA, et al. HIV-specific IL-10-positive CD8+ T cells suppress cytolysis and IL-2 production by CD8+ T cells. J Immunol 2007; 178: 3265-3271.

43. Hosmalin A, Lebon P. Type I interferon production in HIV-infected patients. J Leukoc Biol 2006; 80: 984-993.

44. Pedroza-Martins L, Boscardin WJ, Anisman-Posner DJ, et al. Interferon-gamma decreases replication of primary R5 HIV-1 isolates in thymocytes. AIDS 2006; 20: 939-942.

45. de Castro Cunha RM, Kallas EG, Rodrigues DS, et al. Interferongamma and tumour necrosis factor-alpha production by CD4+ T and CD8+ T lymphocytes in AIDS patients with tuberculosis. Clin Exp Immunol 2005; 140: 491-497.

46. Lewinsohn DA, Heinzel AS, Gardner JM, et al. Mycobacterium tuberculosis-specific CD8+ T cells preferentially recognize heavily infected cells. Am J Respir Crit Care Med 2003; 168: 1346-1352.

47. Lewinsohn DA, Winata E, Swarbrick GM, et al. Immunodominant tuberculosis CD8 antigens preferentially restricted by HLA-B. PLoS Pathog 2007; 3: 1240-1249.

48. Havlir DV, Getahun H, Sanne I, et al. Opportunities and challenges for HIV care in overlapping HIV and TB epidemics. JAMA 2008 300: 423-430.

49. Diedrich CR, O'Hern J, Wilkinson RJ. HIV-1 and the Mycobacterium tuberculosis granuloma: a systematic review and meta-analysis. Tuberculosis (Edinb) 2011; 98: 62-76.

50. Boasso A, Vaccari M, Nilsson J, et al. Do regulatory T-cells play a role in AIDS pathogenesis? AIDS Rev 2006; 8: 141-147.

51. Card CM, McLaren PJ, Wachihi C, et al. Decreased immune activation in resistance to HIV-1 infection is associated with an elevated frequency of CD4(+) CD25(+) FOXP3(+) regulatory T cells. J Infect Dis 2009; 199: 1318-1322.

52. Pawlowski A, Sköld M, Rottenberg ME, et al. Tuberculosis and HIV co-infection. PLoS Pathog 2012; 8: e1002464.

53. Fazekas de St Groth B, Landay AL. Regulatory T cells in HIV infection: pathogenic or protective participants in the immune response? AIDS 2008; 22: 671-683.

54. Elrefaei M, Burke CM, Baker CA, et al. TGF-beta and IL-10 production by HIV-specific CD8+ T cells is regulated by CTLA- 4 signalling on CD4+ T cells. PLoS One 2009; 4: e8194.

55. Baba K, Sornes S, Hoosen AA, et al. Evaluation of immune responses in HIV infected patients with pleural tuberculosis by the QuantiFERON TB-Gold interferon-gamma assay. BMC Infect Dis 2008 8: 35 .

56. Marjani M, Yousefzadeh A, Baghaei P, et al. Impact of HIV infection on tuberculous pleural effusion. Int J STD AIDS 2015; $27: 363-$ 369.

57. Keshinro B, Diul MY. HIV-TB: epidemiology, clinical features and diagnosis of smear-negative TB. Trop Doct 2006; 36: 68-71.

58. Cervio JS. HIV and your immune system. How they work and why it's important. Posit Aware 2009; 20: 17-21.

59. Chaisson RE. TB and HIV: challenges and progress. Hopkins HIV Rep 2002; 14: 8-9.

60. Bishai WR, Chaisson RE. Opportunistic infections: down but not out. Hopkins HIV Rep 1999; 11: 2,7,12.

61. Halsey NA, Coberly J, Chaisson R. Prevention of tuberculosis in HIV-1. Lancet 1998; 352: 742.

62. Chaisson RE, Bishai W. No news is good news: opportunistic infections. Hopkins HIV Rep 1998; 10: 2,11.

63. Shacklett BL, Critchfield JW, Ferre AL, et al. Mucosal T-cell responses to HIV: responding at the front lines. J Intern Med 2009; 265: 58-66.
64. Chaudhry A, Verghese DA, Das SR, et al. HIV-1 Nef promotes endocytosis of cell surface MHC class II molecules via a constitutive pathway. J Immunol 2009; 183: 2415-2424.

65. Chaudhry A, Das SR, Jameel S, et al. A two-pronged mechanism for HIV-1 Nef-mediated endocytosis of immune costimulatory molecules CD80 and CD86. Cell Host Microbe 2007; 1: 37-49.

66. Chaudhry A, Das SR, Hussain A, et al. The Nef protein of HIV-1 induces loss of cell surface costimulatory molecules CD80 and CD86 in APCs. J Immunol 2005; 175: 4566-4574.

67. Addo MM, Draenert R, Rathod A, et al. Fully differentiated HIV-1 specific CD8+ T effector cells are more frequently detectable in controlled than in progressive HIV-1 infection. PLoS One 2007; 2: e321.

68. Kuerten S, Asaad RJ, Schoenberger SP, et al. The TRAIL of helpless CD8+ T cells in HIV infection. AIDS Res Hum Retroviruses 2008; 24: $1175-1183$.

69. De Boer RJ. Understanding the failure of CD8+ T-cell vaccination against simian/human immunodeficiency virus. J Virol 2007; 81: 2838-2848.

70. Achour A, Biquard JM, Krsmanovic V, et al. Induction of human immunodeficiency virus (HIV-1) envelope specific cell-mediated immunity by a non-homologous synthetic peptide. PLoS One 2007; 2: e1214.

71. Agnellini P, Wolint $P$, Rehr M, et al. Impaired NFAT nuclear translocation results in split exhaustion of virus-specific CD8+ T cell functions during chronic viral infection. Proc Natl Acad Sci U S A 2007; 104: 4565-4570.

72. Ali A, Ng HL, Dagarag MD, et al. Evasion of cytotoxic T lymphocytes is a functional constraint maintaining HIV-1 Nef expression. Eur J Immunol 2005; 35: 3221-3228.

73. Lewis MJ, Balamurugan A, Ohno A, et al. Functional adaptation of Nef to the immune milieu of HIV-1 infection in vivo. J Immuno 2008; 180: 4075-4081.

74. Shalekoff S, Meddows-Taylor S, Gray GE, et al. Identification of human immunodeficiency virus- 1 specific CD8+ and CD4+ T cell responses in perinatally-infected infants and their mothers. AIDS 2009; 23: 789-798.

75. Sacha JB, Chung C, Rakasz EG, et al. Gag-specific CD8+ T lymphocytes recognize infected cells before AIDS-virus integration and viral protein expression. J Immunol 2007; 178: 2746-2754.

76. Snyder-Cappione JE, Divekar AA, Maupin GM, et al. HIV-specific cytotoxic cell frequencies measured directly ex vivo by the Lysispot assay can be higher or lower than the frequencies of IFN-gammasecreting cells: anti-HIV cytotoxicity is not generally impaired relative to other chronic virus responses. J Immunol 2006; 176: 2662 2668.

77. Buseyne F, Scott-Algara D, Corre B, et al. Poor recognition of HIV-1 Nef protein by CD8 T cells from HIV-1-infected children: impact of age. Virology 2006; 354: 271-279.

78. Doria-Rose NA, Connors M. Antibody-secreting B cells in HIV infection. Curr Opin HIV AIDS 2009; 4: 426-430.

79. Odinsen O, Parker D, Radebe F, et al. Early detection of human immunodeficiency virus type 1-specific B-lymphocyte-derived antibodies in a high-risk population. Clin Vaccine Immunol 2009; 16: 1060-1065.

80. Moir S, Fauci AS. B cells in HIV infection and disease. Nat Rev Immunol 2009; 9: 235-245.

81. Banki Z, Wilflingseder D, Ammann CG, et al. Factor I-mediated processing of complement fragments on HIV immune complexes targets HIV to CR2-expressing B cells and facilitates B cell-mediated transmission of opsonized HIV to T cells. J Immunol 2006; 177: 3469-3476.

82. Phuah JY, Mattila JT, Lin PL, et al. Activated B cells in the granulomas of nonhuman primates infected with Mycobacterium tuberculosis. Am J Pathol 2012; 181: 508-514.

83. Alam SM, Morelli M, Dennison SM, et al. Role of HIV membrane in neutralization by two broadly neutralizing antibodies. Proc Natl Acad Sci USA 2009; 106: 20234-20239. 
84. Alam SM, Scearce RM, Parks RJ, et al. Human immunodeficiency virus type 1 gp41 antibodies that mask membrane proximal region epitopes: antibody binding kinetics, induction, and potential for regulation in acute infection. J Virol 2008; 82: 115-125.

85. Balla-Jhaghoorsingh SS, Willems B, Heyndrickx L, et al. Characterization of neutralizing profiles in HIV-1 infected patients from whom the HJ16, HGN194, and HK20 mAbs were obtained. PLoS One 2011; 6: e25488.

86. Bonsignori M, Moody MA, Parks RJ, et al. HIV-1 envelope induces memory B cell responses that correlate with plasma antibody levels after envelope gp120 protein vaccination or HIV-1 infection. J Immunol 2009; 183: 2708-2717.

87. Kresge KJ. Identifying broadly neutralizing antibody activity in HIVinfected individuals. IAVI Rep 2009; 13: 18.

88. Montgomery DL, Wang YJ, Hrin R, et al. Affinity maturation and characterization of a human monoclonal antibody against HIV-1 gp41. MAbs 2009; 1: 462-474.

89. Haynes BF, Moody MA, Verkoczy L, et al. Antibody polyspecificity and neutralization of HIV-1: a hypothesis. Hum Antibodies 2005; 14: 59-67.

90. Srivastava IK, Ulmer JB, Barnett SW. Role of neutralizing antibodies in protective immunity against HIV. Hum Vaccin 2005; 1: 45-60.

91. Boliar S, Murphy MK, Tran TC, et al. B-lymphocyte Dysfunction in Chronic HIV-1 Infection Does Not Prevent Cross-clade Neutralization Breadth. J Virol 2012; 86: 10.

92. D'Souza M, Fontenot AP, Mack DG, et al. Programmed death 1 expression on HIV-specific CD4+ T cells is driven by viral replication and associated with T cell dysfunction. J Immunol 2007; 179: 1979-1987.

93. Rosignoli G, Lim CH, Bower M, et al. Programmed death (PD)-1 molecule and its ligand PD-L1 distribution among memory CD4 and CD8 $\mathrm{T}$ cell subsets in human immunodeficiency virus-1-infected individuals. Clin Exp Immunol 2009; 157: 90-97.

94. Day CL, Kaufmann DE, Kiepiela P, et al. PD-1 expression on HIVspecific T cells is associated with T-cell exhaustion and disease progression. Nature 2006; 443: 350-354.

95. Trautmann L, Janbazian L, Chomont N, et al. Upregulation of PD-1 expression on HIV-specific CD8+ T cells leads to reversible immune dysfunction. Nat Med 2006; 12: 1198-1202.

96. Chiodi F. A link between immune hyperactivation of T cells during HIV-1 infection and the virus protease? AIDS 2006; 20: 769-771.

97. Lore K, Karlsson Hedestam GB. Novel adjuvants for B cell immune responses. Curr Opin HIV AIDS 2009; 4: 441-446.

98. Moore PL, Gray ES, Morris L. Specificity of the autologous neutralizing antibody response. Curr Opin HIV AIDS 2009; 4: 358363.

99. Abayneh SA, Ellmark P, Karlsson U, et al. Sensitivity of HIV type 1 primary isolates to human anti-CD40 antibody-mediated suppression is related to coreceptor use. AIDS Res Hum Retroviruses 2008; 24: 447-452.

100. He W, Neil S, Kulkarni H, et al. Duffy antigen receptor for chemokines mediates trans-infection of HIV-1 from red blood cells to target cells and affects HIV-AIDS susceptibility. Cell Host Microbe 2008; 4 52-62.

101. Padmapriyadarsini GNSS C. Diagnosis \& treatment of tuberculosis in HIV co-infected patients. Indian J Med Res 2011; 134: 850-865.

102. Wanchu A. Advances in serology for diagnosing TB in the HIV infected. Indian J Chest Dis Allied Sci 2005; 47: 31-37.

103. Simonney N, Dewulf G, Herrmann JL, et al. Anti-PGL-Tb1 responses as an indicator of the immune restoration syndrome in HIV-TB patients. Tuberculosis (Edinb) 2008; 88: 453-461.

104. Rudnicka D, Schwartz O. Intrusive HIV-1-infected cells. Nat Immunol 2009; 10: 933-934.

105. Balagopal A, Ray SC, De Oca RM, et al. Kupffer cells are depleted with HIV immunodeficiency and partially recovered with antiretroviral immune reconstitution. AIDS 2009; 23: 2397-2404.
106. Azzam R, Kedzierska K, Leeansyah E, et al. Impaired complementmediated phagocytosis by HIV type-1-infected human monocytederived macrophages involves a cAMP-dependent mechanism. AIDS Res Hum Retroviruses 2006; 22: 619-629.

107. Akhtar LN, Qin H, Muldowney MT, et al. Suppressor of cytokine signalling 3 inhibits antiviral IFN-beta signalling to enhance HIV-1 replication in macrophages. J Immunol 2010; 185: 2393-2404.

108. Ahmed N, Hayashi T, Hasegawa A, et al. Suppression of human immunodeficiency virus type 1 replication in macrophages by commensal bacteria preferentially stimulating Toll-like receptor 4 . J Gen Virol 2010; 91: 2804-2813.

109. Yadav A, Fitzgerald P, Sajadi MM, et al. Increased expression of suppressor of cytokine signalling-1 (SOCS-1): A mechanism for dysregulated T helper-1 responses in HIV-1 disease. Virology 2009; 385: 126-133.

110. Minang JT, Trivett MT, Coren LV, et al. Nef-mediated MHC class I down-regulation unmasks clonal differences in virus suppression by SIV-specific CD8(+) T cells independent of IFN-gamma and CD107a responses. Virology 2009; 391: 130-139.

111. Arhel N, Lehmann M, Clauss K, et al. The inability to disrupt the immunological synapse between infected human $\mathrm{T}$ cells and APCs distinguishes HIV-1 from most other primate lentiviruses. J Clin Invest 2009; 119: 2965-2975.

112. Chaudhry A, Das SR, Jameel S, et al. HIV-1 Nef induces a Rab11-dependent routing of endocytosed immune costimulatory proteins CD80 and CD86 to the Golgi. Traffic 2008; 9: 1925-1935.

113. Redford PS. The role of IL-10 in immune regulation during M. tuberculosis infection. Mucosal Immunology 2011; 4: 261-270.

114. Srikanth P, Sridharan G, John TJ, et al. Increase in plasma IL-10 levels and rapid loss of CD4+ T cells among HIV-infected individuals in south India. Int J STD AIDS 2000; 11: 49-51.

115. Nowroozalizadeh S, Mansson F, da Silva Z, et al. Studies on toll-like receptor stimuli responsiveness in HIV-1 and HIV-2 infections. Cytokine 2009; 46: 325-331.

116. Brown JN, Kohler JJ, Coberley CR, et al. HIV-1 activates macrophages independent of Toll-like receptors. PLoS One 2008; 3: e3664.

117. Lester RT, Yao XD, Ball TB, et al. Toll-like receptor expression and responsiveness are increased in viraemic HIV-1 infection. AIDS 2008; 22: 685-694.

118. Tsang J, Chain BM, Miller RF, et al. HIV-1 infection of macrophages is dependent on evasion of innate immune cellular activation. AIDS 2009; 23: 2255-2263.

119. Ahmed Z, Czubala M, Blanchet F, et al. HIV impairment of immune responses in dendritic cells. Adv Exp Med Biol 2012; 762: 201-238.

120. Ahmed Z, Kawamura T, Shimada S, et al. The role of human dendritic cells in HIV-1 infection. J Invest Dermatol 2014; 135: 12251233.

121. Pouliot K, Buglione-Corbett R, Marty-Roix R, et al. Contribution of TLR4 and MyD88 for adjuvant monophosphoryl lipid A (MPLA) activity in a DNA prime-protein boost HIV-1 vaccine. Vaccine 2014; 32: 5049-5056.

122. Planes R, Ben Haij N, Leghmari K, et al. HIV-1 Tat protein activates both MyD88 and TRIF pathways to induce TNF-alpha and IL-10 in human monocytes. J Virol 2016; 90: 5886-5898.

123. Pathak S, De Souza GA, Salte T, et al. HIV induces both a down-regulation of IRAK-4 that impairs TLR signalling and an up-regulation of the antibiotic peptide dermcidin in monocytic cells. Scand J Immunol 2009; 70: 264-276.

124. Cassol E, Cassetta L, Rizzi C, et al. M1 and M2a polarization of human monocyte-derived macrophages inhibits HIV-1 replication by distinct mechanisms. J Immunol 2009; 182: 6237-6246.

125. Cassetta L, Cassol E, Poli G. Macrophage polarization in health and disease. Sci World J 2011; 11: 2391-2402.

126. Torheim EA, Ndhlovu LC, Pettersen FO, et al. Interleukin-10-secreting T cells define a suppressive subset within the HIV-1-specific T-cell population. Eur J Immunol 2009; 39: 1280-1287. 
127. Kared H, Lelievre JD, Donkova-Petrini V, et al. HIV-specific regulatory $\mathrm{T}$ cells are associated with higher $\mathrm{CD} 4$ cell counts in primary infection. AIDS 2008; 22: 2451-2460.

128. Bergamini FB, Fagioli E, Placido R, et al. HIV-1 does not alter in vitro and in vivo IL-10 production by human monocytes and macrophages. Clin Exp Immunol 1998; 112: 7.

129. Pauls E, Jimenez E, Ruiz A, et al. Restriction of HIV-1 replication in primary macrophages by IL-12 and IL-18 through the upregulation of SAMHD1. J Immunol 2013; 190: 4736-4741.

130. Rodriguez-Frade JM, Munoz LM, Holgado BL, et al. Chemokine receptor dimerization and chemotaxis. Methods Mol Biol 2009; 571: 179-198.

131. Brito A, Rigato PO, Almeida A, et al. Chemokine receptors expression on T cells and response to HAART among chronic HIV-1-infected subjects. Curr HIV Res 2008; 6: 539-543.

132. Roe B, Coughlan S, Hassan J, et al. Elevated serum levels of interferon-gamma-inducible protein-10 in patients coinfected with hepatitis C virus and HIV. J Infect Dis 2007; 196: 1053-1057.

133. Cinque P, Bestetti A, Marenzi R, et al. Cerebrospinal fluid interferon-gamma-inducible protein 10 (IP-10, CXCL10) in HIV-1 infection. J Neuroimmunol 2005; 168: 154-163.

134. Kumar SB, Rice CE, Milner DA Jr, et al. Elevated cytokine and chemokine levels in the placenta are associated with in-utero HIV-1 mother-to-child transmission. AIDS 2012; 26: 685-694.

135. Mosier DE. How HIV changes its tropism: evolution and adaptation? Curr Opin HIV AIDS 2009; 4: 125-130.

136. Coetzer M, Nedellec R, Salkowitz J, et al. Evolution of CCR5 use before and during coreceptor switching. J Virol 2008; 82: 11758-11766.

137. Lederman MM, Penn-Nicholson A, Cho M, et al. Biology of CCR5 and its role in HIV infection and treatment. JAMA 2006; 296: 815826.

138. Biancotto A, Grivel JC, Lisco A, et al. Evolution of SIV toward RANTES resistance in macaques rapidly progressing to AIDS upon coinfection with HHV-6A. Retrovirology 2009; 6: 61.

139. Ananworanich J. What Will It Take to Cure HIV? Top Antivir Med 2015; 23: 80-84

140. Cashin K, Jakobsen MR, Sterjovski J, et al. Linkages between HIV-1 specificity for CCR5 or CXCR4 and in vitro usage of alternative coreceptors during progressive HIV-1 subtype C infection. Retrovirology 2013; 10: 98.

141. Coffey MJ, Woffendin C, Phare SM, et al. RANTES inhibits HIV-1 replication in human peripheral blood monocytes and alveolar macrophages. Am J Physiol 1997; 272: L1025-1029.

142. Kasama T, Yajima N, Matsukura S, et al. Macrophage inflammatory protein 1 and CCR5 as attractive therapeutic targets for HIV infection. Recent Pat Antiinfect Drug Discov 2006; 1: 275-280.

143. Chandrasekaran P, Moore V, Buckley M, et al. HIV-1 Nef down -modulates $\mathrm{C}-\mathrm{C}$ and $\mathrm{C}-\mathrm{X}-\mathrm{C}$ chemokine receptors via ubiquitin and ubiquitin-independent mechanism. PLoS One 2014; 9: e86998.

144. Jin J, Colin P, Staropoli I, et al. Targeting spare CC chemokine receptor 5 (CCR5) as a principle to inhibit HIV-1 entry. J Biol Chem 2014; 289: 19042-19052.

145. Kalsdorf B, Skolimowska KH, Scriba TJ, et al. Relationship between chemokine receptor expression, chemokine levels and HIV-1 replication in the lungs of persons exposed to Mycobacterium tuberculosis. Eur J Immunol 2012; 43: 540-549.

146. Sun L, Zhang Y, Huang CX, et al. Therapeutic effect of RANTESKDEL on inhibition of HIV-1 in CD34(+) human hematopoietic stem cells (hHSC). J Virol Methods 2008; 154: 194-199.

147. Mavigner M, Delobel P, Cazabat M, et al. HIV-1 residual viremia correlates with persistent T-cell activation in poor immunological responders to combination antiretroviral therapy. PLoS One 2009; 4: e7658.

148. Savage P, Millrain M, Dimakou S, et al. Expansion of CD8+ cytotoxic $\mathrm{T}$ cells in vitro and in vivo using MHC class I tetramers Tumour Biol 2007; 8: 70-76.
149. Scriba TJ, Purbhoo M, Day CL, et al. Ultrasensitive detection and phenotyping of CD4+ T cells with optimized HLA class II tetramer staining. J Immunol 2005; 175: 6334-6343.

150. Goulder PJ, Altfeld MA, Rosenberg ES, et al. Substantial differences in specificity of HIV-specific cytotoxic T cells in acute and chronic HIV infection. J Exp Med 2001; 193: 181-194.

151. Connick E, Mattila T, Folkvord JM, et al. CTL fail to accumulate at sites of HIV-1 replication in lymphoid tissue. J Immunol 2007; 178 6975-6983.

152. Dorrell L, Yang H, Ondondo B, et al. Expansion and diversification of virus-specific $\mathrm{T}$ cells following immunization of human immunodeficiency virus type 1 (HIV-1)-infected individuals with a recombinant modified vaccinia virus Ankara/HIV-1 Gag vaccine. J Virol 2006; 80: 4705-4716.

153. Benito JM, Lopez M, Soriano V. The role of CD8+ T-cell response in HIV infection. AIDS Rev 2004; 6: 79-88.

154. Lopez A, van der Lubbe N, Sanchez-Palomino S, et al. Phenotypic and functional characteristics of HIV-specific CD8 T cells and gag sequence variability after autologous dendritic cells based therapeutic vaccine. Vaccine 2009; 27: 6166-6178.

155. Masopust D. Developing an HIV cytotoxic T-lymphocyte vaccine issues of CD8 T-cell quantity, quality and location. J Intern Med 2009; 265: 125-137.

156. Rollman E, Smith MZ, Brooks AG, et al. Killing kinetics of simian immunodeficiency virus-specific CD8+ T cells: implications for HIV vaccine strategies. J Immunol 2007; 179: 4571-4579.

157. Poccia F, Wallace M, Colizzi V, et al. Possible protective and pathogenic roles of gamma delta T lymphocytes in HIV-infections (Review). Int J Mol Med 1998; 1: 409-413.

158. Riedel DJ, Sajadi MM, Armstrong CL, et al. Natural viral suppressors of HIV-1 have a unique capacity to maintain gammadelta T cells. AIDS 2009; 23: 1955-1964.

159. Lehner T, Wang Y, Pido-Lopez J, et al. The emerging role of innate immunity in protection against HIV-1 infection. Vaccine 2008; 26 : 2997-3001.

160. Fenoglio D, Poggi A, Catellani S, et al. Vdelta1 T lymphocytes producing IFN-gamma and IL-17 are expanded in HIV-1-infected patients and respond to Candida albicans. Blood 2009; 113: 66116618.

161. Rai AK, Thakur CP, Seth T, et al. Early activated Th-1 type and dominantly diverse natural killer T (CD3(+) CD161 (+) Valpha24(-)) cells in bone marrow among visceral leishmaniasis patients. Int J Parasitol 2011; 41: 1069-1077.

162. Tsuji M. Glycolipids and phospholipids as natural CD1d-binding NKT cell ligands. Cell Mol Life Sci 2006; 63: 1889-1898.

163. Li D, Xu XN. NKT cells in HIV-1 infection. Cell Res 2008; 18: 817 822 .

164. van der Vliet HJ, van Vonderen MG, Molling JW, et al. Cutting edge: Rapid recovery of NKT cells upon institution of highly active antiretroviral therapy for HIV-1 infection. J Immunol 2006; 177: 5775-5778.

165. Chen N, McCarthy C, Drakesmith H, et al. HIV-1 down-regulates the expression of CD1d via Nef. Eur J Immunol 2006; 36: 278-286.

166. Moreno-Fernandez ME, Zapata W, Blackard JT, et al. Human regulatory $\mathrm{T}$ cells are targets for human immunodeficiency virus (HIV) infection, and their susceptibility differs depending on the HIV type 1 strain. J Virol 2009; 83: 12925-12933.

167. Cao W, Jamieson BD, Hultin LE, et al. Regulatory T cell expansion and immune activation during untreated HIV type 1 infection are associated with disease progression. AIDS Res Hum Retroviruses 2009; 25: 183-191

168. Ji J, Cloyd MW. HIV-1 binding to CD4 on CD4+CD25+ regulatory $\mathrm{T}$ cells enhances their suppressive function and induces them to home to, and accumulate in, peripheral and mucosal lymphoid tissues: an additional mechanism of immunosuppression. Int Immunol 2009; 21: 283-294 
169. Kaufmann DE, Walker BD. PD-1 and CTLA-4 inhibitory cosignalling pathways in HIV infection and the potential for therapeutic intervention. J Immunol 2009; 182: 5891-5897.

170. Mexas AM, Fogle JE, Tompkins WA, et al. CD4+CD25+ regulatory $\mathrm{T}$ cells are infected and activated during acute FIV infection. Vet Immunol Immunopathol 2008; 126: 263-272.

171. Porichis F, Kaufmann DE. Role of PD-1 in HIV pathogenesis and as target for therapy. Curr HIV/AIDS Rep 2012; 9: 81-90.

172. Bahraoui E, Briant L, Chazal N. E5564 inhibits immunosuppressive cytokine IL-10 induction promoted by HIV-1 Tat protein. Virol J 2014; 11: 214.

173. Ben Haij N, Leghmari K, Planes R, et al. HIV-1 Tat protein binds to TLR4-MD2 and signals to induce TNF-alpha and IL-10. Retrovirology 2013; 10: 123.

174. Clutton G, Bridgeman A, Reyes-Sandoval A, et al. Transient IL-10 receptor blockade can enhance $\mathrm{CD} 8(+) \mathrm{T}$ cell responses to a simian adenovirus-vectored HIV-1 conserved region immunogen. Hum Vaccin Immunother 2015; 11: 1030-1035.

175. Ramaseri HS, Sunder S, Nagaraju RT, et al. IL-10 high producing genotype predisposes HIV infected individuals to TB infection. Hum Immunol 2012; 73: 605-611.

176. Mihret A, Abebe M, Bekele Y, et al. Impact of HIV co-infection on plasma level of cytokines and chemokines of pulmonary tuberculosis patients. BMC Infect Dis 2014; 14: 125.

177. Amar Singh ABD, Mohan A, Kumar Sharma P, et al. Foxp3+ Regulatory T Cells among Tuberculosis Patients: Impact on Prognosis and Restoration of Antigen Specific IFN- $\gamma$ Producing T Cells. PLoS One 2012; 7: e44728.

178. Sharma PK, Singh A, Sharma SK, et al. FoxP3+ Regulatory T Cells Suppress Effector T-Cell Function at Pathologic Site in Miliary Tuberculosis. Am J Respir Crit Care Med 2009; 179: 1061-1070.

179. Paranjape RS. Immunopathogenesis of HIV infection. Indian J Med Res 2005; 121: 240-255.

180. Paiardini M, Frank I, Pandrea I, et al. Mucosal immune dysfunction in AIDS pathogenesis. AIDS Rev 2008; 10: 36-46.

181. Hu H, Fernando K, Ni H, et al. HIV envelope suppresses CD4+ T cell activation independent of T regulatory cells. J Immunol 2008; 180: 5593-5600.

182. Muthu S, Cecelia AJ, Pulimi S, et al. C-reactive protein in HIV-infected patients - could it be a marker of immunosuppression? Clin Chim Acta 2007; 376: 246-247.

183. Singh KK, Gray PK, Wang Y, et al. HLA alleles are associated with altered risk for disease progression and central nervous system impairment of HIV-infected children. J Acquir Immune Defic Syndr 2011; 57: 32-39.

184. Ngandu NG, Bredell H, Gray CM, et al. CTL response to HIV type 1 subtype $\mathrm{C}$ is poorly predicted by known epitope motifs. AIDS Res Hum Retroviruses 2007; 23: 1033-1041.

185. Singh P, Kaur G, Sharma G, et al. Immunogenetic basis of HIV-1 infection, transmission and disease progression. Vaccine 2008; 26 : 2966-2980.

186. Kaur G, Mehra N. Genetic determinants of HIV-1 infection and progression to AIDS: susceptibility to HIV infection. Tissue Antigens 2009; 73: 289-301.

187. Sironi M, Biasin M, Cagliani R, et al. A common polymorphism in TLR3 confers natural resistance to HIV-1 infection. J Immunol 2012; 188: 818-823.

188. Kader M, Wang X, Piatak M, et al. Alpha4(+) beta7(hi)CD4(+) memory $\mathrm{T}$ cells harbor most $\mathrm{Th}-17$ cells and are preferentially infected during acute SIV infection. Mucosal Immunol 2009; 2: 439-449.

189. Khvedelidze M, Chkhartishvili N, Abashidze L, et al. Expansion of CD3/ CD16/ CD56 positive NKT cells in HIV/ AIDS: the pilot study. Georgian Med News 2008; 165: 78-83.

190. Vazquez E. OIs and co-infections and STDs. Staying healthy with HIV by keeping on top of bugs and such. Posit Aware 2009; 20: 22-23.
191. Lakhashe S, Thakar M, Godbole S, et al. HIV infection in India: epidemiology, molecular epidemiology and pathogenesis. J Biosci 2008; 33: 515-525.

192. Mehendale SM, Bollinger RC, Kulkarni SS, et al. Rapid disease progression in human immunodeficiency virus type 1-infected seroconverters in India. AIDS Res Hum Retroviruses 2002; 18: 1175-1179.

193. Shen Y, Shen L, Sehgal P, et al. Clinical latency and reactivation of AIDS-related mycobacterial infections. J Virol 2004; 78: 1402314032.

194. Tossing G. Therapy of chronic hepatitis B and C and treatment options in HCV-HIV co-infection - European Conference on Infectious Diseases and Tropical Medicine. EuCID 2001, 3-6 May 2001, Leipzig. Eur J Med Res 2001; 6: 272-274.

195. Fidel Jr PL. Candida-host interactions in HIV disease: relationships in oropharyngeal candidiasis. Adv Dent Res 2006; 19: 80-84.

196. Samaranayake LP, Fidel PL, Naglik JR, et al. Fungal infections associated with HIV infection. Oral Dis 2002; 8 Suppl 2: 151-160.

197. UNAIDS. Biomedical AIDS research: Recent and upcoming advances, 2016, pp. 1-30. Available at: http://www.unaids.org/en/resources/documents/2016/2016reference_biomedical-aids-research.

198. Haddow LJ, Easterbrook PJ, Mosam A, et al. Defining immune reconstitution inflammatory syndrome: evaluation of expert opinion versus 2 case definitions in a South African cohort. Clin Infect Dis 2009; 49: 1424-1432.

199. Ahmad Khan F, Verkuijl S, Parrish A, et al. Performance of symptom-based tuberculosis screening among people living with HIV: not as great as hoped. AIDS 2014; 28: 1463-1472.

200. Enserink M. Public health. In the HIV era, an old TB vaccine causes new problems. Science 2007; 318: 1059

201. Faurholt-Jepsen D, Range N, Praygod G, et al. BCG protects against tuberculosis irrespective of HIV status: a matched case-control study in Mwanza, Tanzania. Thorax 2012; 68: 288-289.

202. Harries AD. Applying advances to the developing world for TB and HIV control. Int J Tuberc Lung Dis 2000; 4: S65-70.

203. Hesseling AC, Jaspan HB, Black GF, et al. Immunogenicity of BCG in HIV-exposed and non-exposed infants following routine birth or delayed vaccination. Int J Tuberc Lung Dis 2015; 19: 454-462.

204. Arbeláez MP. BCG vaccine effectiveness in preventing tuberculosis and its interaction with human immunodeficiency virus infection. Int J Epidemiol 2000; 29: 1085-1091. 